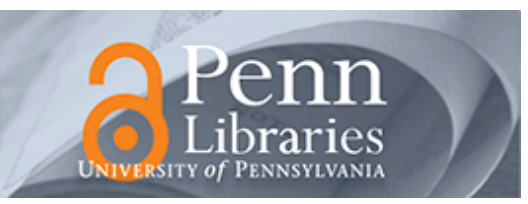

University of Pennsylvania ScholarlyCommons

December 2002

\title{
Imaging, Structural and Chemical Analysis of Silicon Nanowires
}

\author{
R. J. Barsotti Jr. \\ Massachusetts Institute of Technology \\ John E. Fischer \\ University of Pennsylvania, fischer@seas.upenn.edu \\ C. H. Lee \\ Korea Advanced Institute of Science and Technology \\ J. Mahmood \\ University of Pennsylvania, jmahmood@seas.upenn.edu \\ Kofi W. Adu \\ Pennsylvania State University
}

See next page for additional authors

Follow this and additional works at: https://repository.upenn.edu/mse_papers

\section{Recommended Citation}

Barsotti, R. J., Fischer, J. E., Lee, C. H., Mahmood, J., Adu, K. W., \& Eklund, P. C. (2002). Imaging, Structural and Chemical Analysis of Silicon Nanowires. Retrieved from https://repository.upenn.edu/mse_papers/25

Copyright Materials Research Society. Reprinted from MRS Proceedings Volume 737.

Symposium Title: Nanocrystalline Semiconductor Materials and Devices

Proceedings Title: Quantum Confined Semiconductor Nanostructures

2002 Fall Meeting Symposium F

Publisher URL: http://www.mrs.org/members/proceedings/fall2002/f/F6_8.pdf

This paper is posted at ScholarlyCommons. https://repository.upenn.edu/mse_papers/25

For more information, please contact repository@pobox.upenn.edu. 


\title{
Imaging, Structural and Chemical Analysis of Silicon Nanowires
}

\author{
Abstract \\ Laser ablation has been used to grow silicon nanowires with an average diameter of $6.7 \mathrm{~nm} \pm 2.7 \mathrm{~nm}$ \\ surrounded by an amorphous $\mathrm{SiO}_{x}$ sheath of 1-2 $\mathrm{nm}$. This paper reports the imaging, chemical and \\ structural analysis of these wires. Due to the growth temperature and the presence of calcium impurities \\ and trace oxygen, two distinct types of wires are found. They appear to grow by two different processes. \\ One requires a metal catalyst, the other is catalyzed by oxygen.

\section{Comments} \\ Copyright Materials Research Society. Reprinted from MRS Proceedings Volume 737. \\ Symposium Title: Nanocrystalline Semiconductor Materials and Devices \\ Proceedings Title: Quantum Confined Semiconductor Nanostructures \\ 2002 Fall Meeting Symposium F \\ Publisher URL: http://www.mrs.org/members/proceedings/fall2002/f/F6_8.pdf

\section{Author(s)} \\ R. J. Barsotti Jr., John E. Fischer, C. H. Lee, J. Mahmood, Kofi W. Adu, and Peter C. Eklund
}




\title{
Imaging, Structural and Chemical Analysis of Silicon Nanowires
}

\author{
R. J. Barsotti, Jr. ${ }^{1 \#}$, J. E. Fischer ${ }^{1, *}$, C. H. Lee ${ }^{1 \&}$, J. Mahmood ${ }^{1}$, C. K. W. Adu ${ }^{2}$ \\ and P. C. Eklund ${ }^{2,3}$ \\ ${ }^{1}$ Department of Materials Science and Engineering, University of Pennsylvania, \\ Philadelphia, PA 19104 \\ ${ }^{2}$ Department of Physics, The Pennsylvania State University, \\ University Park, PA 16802 \\ ${ }^{3}$ Department of Materials Science and Engineering, The Pennsylvania State University, \\ University Park, PA 16802 \\ ${ }^{\#}$ Current address: Department of Materials Science and Engineering, Massachusetts \\ Institute of Technology, Cambridge, MA 02139 \\ \&Current address: Department of Material Science and Engineering, KAIST, Daejon, \\ Korea \\ *fischer@sol1.lrsm.upenn.edu
}

\begin{abstract}
Laser ablation has been used to grow silicon nanowires with an average diameter of $6.7 \mathrm{~nm} \pm 2.7 \mathrm{~nm}$ surrounded by an amorphous $\mathrm{SiO}_{\mathrm{x}}$ sheath of 1-2 nm. This paper reports the imaging, chemical and structural analysis of these wires. Due to the growth temperature and the presence of calcium impurities and trace oxygen, two distinct types of wires are found. They appear to grow by two different processes. One requires a metal catalyst, the other is catalyzed by oxygen.
\end{abstract}

\section{INTRODUCTION}

Over the past ten years, interest has grown in one-dimensional nanostructures in both academic and industrial communities. Semiconducting nanowires have controllable electronic properties making them a leading candidate for applications [1-6]. Here we report the structural and chemical characterization of small-diameter semiconducting nanowires and propose a growth mechanism based on this analysis.

\section{EXPERIMENTAL DETAILS}

Nanowire material was prepared using the pulsed laser vaporization (PLV) technique [7-10]. A mixture of $\mathrm{Si} \mathrm{(90} \mathrm{at. \% )} \mathrm{and} \mathrm{Fe}$ (10 at.\%) powders were hot pressed into a disc $12 \mathrm{~mm}$ in diameter and $8 \mathrm{~mm}$ thick. This target was placed in the center of a $25 \mathrm{~mm}$ diameter quartz tube which could be heated to $1100^{\circ} \mathrm{C}$. During growth, preheated argon flowed down the tube at a rate of $100 \mathrm{sccm}$ at 500 Torr. A Nd:YAG laser (model SL803, Spectron Laser Systems) with $1064 \mathrm{~nm}$ ( $850 \mathrm{~mJ} / \mathrm{pulse}$ ) and $532 \mathrm{~nm}$ $(350 \mathrm{~mJ} / \mathrm{pulse})$ at $10 \mathrm{~Hz}$ repetition rate was used to ablate the target by rastering the beam with a motorized lens. The $1064 \mathrm{~nm}$ pulse was delayed by 50 nanoseconds relative to the $532 \mathrm{~nm}$ pulse. The argon gas reversed the flow of the $\mathrm{Si} / \mathrm{Fe}$ vapor. Nanowire material was found deposited on the walls of the tube for a distance of up to $10 \mathrm{~cm}$ behind the target. This PLV method produced silicon nanowires with an average diameter of $6.7 \mathrm{~nm}$ 
$\pm 2.7 \mathrm{~nm}$ surrounded by an amorphous $\mathrm{SiO}_{\mathrm{x}}$ sheath of 1-2 nm, comparable in dimension to those produced by a similar method by Lieber[7]. Similarly, Si-Ge nanowires were prepared from a target of $\mathrm{Si}$ (45 at. \%), Ge (45 at. \%) and $\mathrm{Au}(5$ at. \%) at a synthesis temperature of $1050^{\circ} \mathrm{C}$. Ge nanowires were prepared from a target of $\mathrm{Ge}(95$ at. \%) and $\mathrm{Au}\left(5\right.$ at. \%) at a temperature of $1050{ }^{\circ} \mathrm{C}$. For microscopy studies, the nanowire material was sonicated and dispersed in ethanol.

\section{DISCUSSION}

Imaging and analysis was performed on a JEOL 2010 transmission electron microscope. We found and studied two types of silicon nanowires; isolated longer nanowires $(5-10 \mu \mathrm{m})$ which have few attached nanoparticles, and clustered shorter wires $(100-500 \mathrm{~nm})$ connected by many nanoparticles, forming nanochains (Figure 1). Of particular interest are the $360^{\circ}$ loops with diameters as small as $100 \mathrm{~nm}$ (Figure 1 (B)). Electron beam diffraction on $\mathrm{Si}$ nanowire loops demonstrate that the straight segments of the nanowires are crystalline while the areas of high curvature are amorphous. This may indicate that a short segment of the crystalline wire entered a high temperature zone during growth and melted. The wire deformed due to its weight and was quenched in an amorphous state. Similar loops were formed in the TEM when the electron beam was focused on a small spot of a thin Si nanowire.

Chemical analysis was performed with energy dispersive spectroscopy (EDS) in scanning transmission electron microscopy (STEM) mode. The Si nanowires contained silicon and oxygen, suggesting a silicon core surrounded by a $\mathrm{SiO}_{\mathrm{x}}$ sheath. The particles which had been assumed to be $\mathrm{FeSi}_{2}$ showed a significant amount of $\mathrm{Ca}$ (Figure 1 (D)) but no $\mathrm{Fe}$. Ca-Si particles were found at the end of longer nanowires; nanochains also contained many mid-chain Si-Ca nanoparticles. The balls used to mill and mix the Fe and Si powders were found to be the source of $\mathrm{Ca}$ contamination. Nanoparticles which contained only Si and $\mathrm{O}$ were found as part of the nanochains.

The morphology and chemical analysis suggest that the Si nanowires were grown
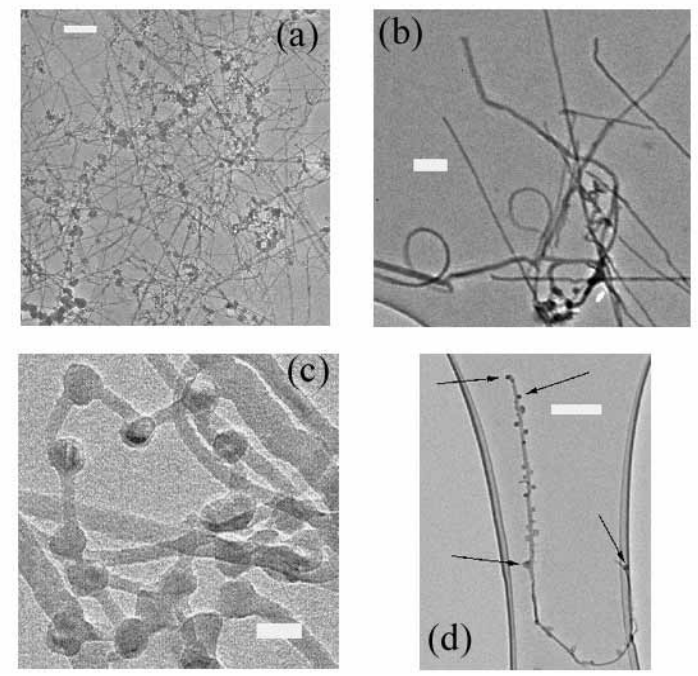

Figure 1: (A) Low magnification TEM image of silicon nanowires; scale bar: $200 \mathrm{~nm}$. (B) TEM image of 5-10 micron long nanowires showing $360^{\circ}$ loops; scale bar: $100 \mathrm{~nm}$. (C) STEM image of nanochains; scale bar: $25 \mathrm{~nm}$. (D) Arrows indicate Ca-Si nanoparticles; scale bar: $250 \mathrm{~nm}$. 
by two separate mechanisms. The 5-10 micron long nanowires appear to grow via the vapor-liquid-solid mechanism (VLS) (Figure 2 (A)) [7, 11]. Growth is expected to terminate when the catalyst particle crystallizes into $\mathrm{FeSi}_{2}$ or $\mathrm{CaSi}_{2}$. Ca-Si has a lower eutectic temperature of $1030^{\circ} \mathrm{C}(61.4 \mathrm{wt} . \% \mathrm{Si})$ compared to $1207^{\circ} \mathrm{C}$ for $\mathrm{Fe}-\mathrm{Si}(58.2$ wt.\% Si). This may favor growth by Ca catalysis at the growth temperature of $1100^{\circ} \mathrm{C}$.

The VLS model cannot explain the growth of nanochains. The oxide assisted growth mode1 [9, 12-14] (Figure 2 (B)) applied to a laser ablation system where Si, O and $\mathrm{Ca}$ are present, can account for the growth of nanochains. $\mathrm{SiO}_{\mathrm{x}}$ vapor is formed by the ablation of oxidized $\mathrm{Si}$ grains in the target. $\mathrm{SiO}_{\mathrm{x}}$ nanoparticles can nucleate on the side of the quartz tube. $\mathrm{SiO}_{x}$ particles then begin to decompose into $\mathrm{Si}$ and $\mathrm{SiO}_{2}$. A wire of crystalline silicon surrounded by an amorphous $\mathrm{SiO}_{2}$ sheath is then formed. $\mathrm{SiO}_{\mathrm{x}}$ and $\mathrm{Si}$ vapor continue to fall on the tip of the nanowire. Decomposition leads to nanowire growth which is restricted to one direction by the $\mathrm{SiO}_{2}$ sheath. $\mathrm{SiO}_{\mathrm{x}}$ may land on the tip and crystallize in a growth direction which is not energetically favorable. Another inhibitor of nanowire nucleation may be the existence of $\mathrm{Ca}$ in the $\mathrm{SiO}_{\mathrm{x}}$ vapor. $\mathrm{Si}$ and $\mathrm{O}$ build up around the either the nanowire attempting to grow in an unfavorable growth direction, or the $\mathrm{Ca}$ impurity. This causes the formation of large spherical particles, as observed in the nanochains. Additional $\mathrm{SiO}_{\mathrm{x}}$ vapor impinges upon the particle, and $\mathrm{Si}$ begins to crystallize in a favorable direction, allowing a nanowire to nucleate from the particle.

We propose that the $1100^{\circ} \mathrm{C}$ target temperature permits growth by both VLS and oxide-assisted mechanisms to occur simultaneously, and that the two mechanisms produce the two distinct types of wires found in the sample: 5-10 micron, long nanowires and nanochains. The measured temperature gradient in the furnace is consistent with the possibility that regions within $10 \mathrm{~cm}$ of the target are at $1070^{\circ} \mathrm{C}$, allowing for nucleation of silicon nanowires by the oxide assisted model [9]. Areas closer to the target would be at temperatures optimal for VLS growth catalyzed by $\mathrm{CaSi}_{\mathrm{x}}$, and possibly also by $\mathrm{FeSi}_{\mathrm{x}}$, near $1100^{\circ} \mathrm{C}$ (if the melting point is depressed by the small particle size). The Si-Ge wires showed a similar morphology consisting of both long nanowires and nanochains. Chemical analysis suggested that the wires followed the above growth mechanisms. In

(a) Vapor Liquid Solid Growth Mechanism?
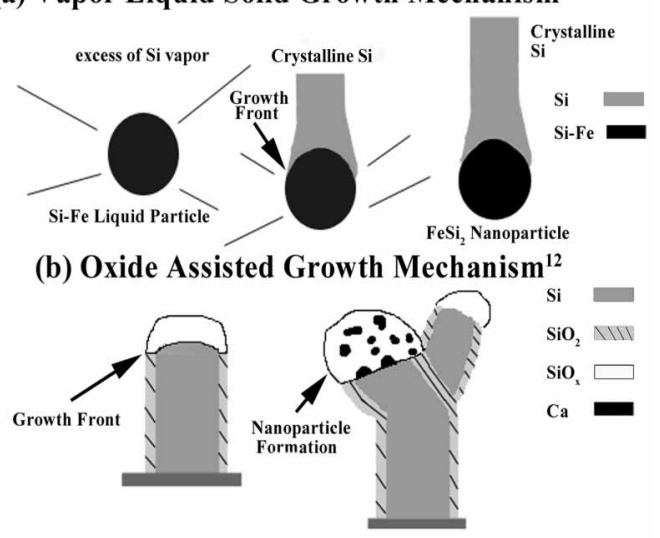

Figure 2: (A) (1) In the VLS growth mechanism, a Si-Fe liquid nanoparticle becomes supersaturated with Si vapor. (2) Crystalline silicon, in thermodynamic equilibrium with the liquid $\mathrm{Si}$-Fe nanoparticle, precipitates out. (3) Growth terminates when the nanoparticle is pushed into a cooler region of the tube, where it crystallizes into $\mathrm{FeSi}_{2}$.

(B) (1) In the Oxide Assisted Growth Model, growth occurs when $\mathrm{SiO}_{\mathrm{x}}$ vapor condenses on the side of the quartz tube and decomposes into SiO and $\mathrm{SiO}_{2}$. Additonal $\mathrm{SiO}_{x}$ vapor lands on the tip of the wire and growth continues in one direction. (2) Nanoparticle formation occurs when calcium vapor inhibits the formation of $\mathrm{Si}$ and $\mathrm{SiO}_{2}$. Renucleation occurs and growth continues along a new direction. 

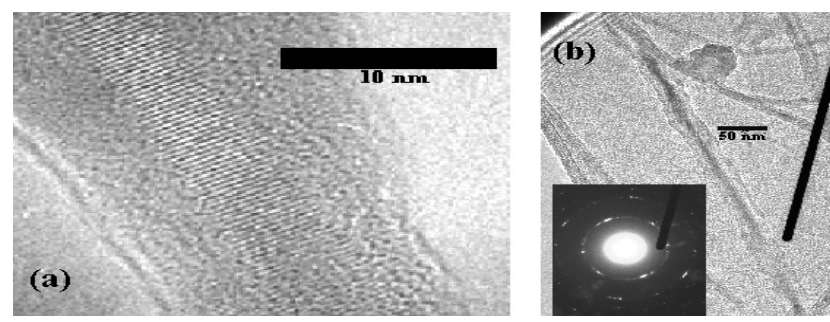

Figure 3: (A) High resolution TEM image showing $\{111\}$ planes aligned perpendicular to the axis. (B) Electron diffraction of a long, straight nanowire showing <111> growth direction.

the pure Ge samples, only long Ge nanowires, grown via the VLS mechanism, were found. Ge nanowires were grown at a temperature of $1050 \mathrm{C}$, which is too high for the reported range of favorable temperatures for the oxide assisted growth mechanism of $\mathrm{Ge}$ nanowires, $690-705^{\circ} \mathrm{C}[13]$.

High resolution TEM revealed several other features in the nanowires (Figure 3). The spacing between the lattice fringes in the core of the nanowire is $3.1 \AA$, signifying that they are $\mathrm{Si}\{111\}$ planes. These are oriented perpendicular to the nanowire axis indicating a $<111>$ growth direction. High resolution TEM images also show nanowires whose $\{111\}$ planes are oriented at angles of $60^{\circ}-70^{\circ}$ to the growth direction $\left(30^{\circ}-20^{\circ}\right.$ to the perpendicular), suggesting a $<211>$ growth direction as the [211] and [111] directions are $19.47^{\circ}$ apart.

Electron diffraction was performed to confirm the growth directions of 5-10 $\mu \mathrm{m}$ $\mathrm{Si}$ wires and Si nanochains (Figure 3). Most of the long wires grow in the <111> direction, suggesting that the VLS mechanism favors this growth mode. Si nanochains were found to grow in both $<111>$ and $<211>$ directions, suggesting that oxide-assisted growth does not strongly favor any particular growth direction. High resolution TEM and electron diffraction showed that the Ge nanowires, grown via the VLS mechanism, exhibited a $<111>$ growth direction.

\section{CONCLUSION}

In summary, we have reported the imaging and structural analysis of silicon nanowires produced by laser vaporization of $\mathrm{Si}(90 \%)$ - Fe (10\%) targets. The nanowires are grown by two distinct growth mechanisms, which were both possible due to growth conditions. The two growth mechanisms produce wires with different morphologies that exhibit different crystallographic growth directions and stem from nanoparticles with different chemical compositions.

\section{ACKNOWLEDGMENTS}

This work was supported at Penn and Penn State by the National Science Foundation MRSEC Program, Grant No. DMR00-79909. 


\section{REFERENCES}

1. Z. Zhang, X. H. Fan, L. Xu, C. S. Lee and S. T. Lee, Chem. Phys. Letters 337, 18 (2001).

2. J. Yu, S. Chung and J. Heath, J. Phys. Chem. B 104, 11864 (2000).

3. Y. Cui, X. Duan, J. Hu and C. M. Lieber, J. Phys. Chem. B 104, 5213 (2000).

4. Y. Huang, X. Duan, Q. Wei and C. M. Lieber, Science 291, 630 (2001).

5. Y. Cui and C. M. Lieber, Science 291, 851 (2001).

6. Y. Huang, X. Duan, Y. Cui, L. J. Lauhon, K. Kim and C. M. Lieber, Science 294, 1313 (2001).

7. A.M. Morales and C. M. Lieber, Science 279, 208 (1998).

8. Y.F. Zhang, Y. H Tang, N. Wang, D. P. Yu, C. S. Lee, I. Bello, and S. T. Lee, Appl. Phys. Letters 72, 1835 (1998).

9. Y. H. Tang, Y.F. Zhang, N. Wang, W.S. Shi, C.S. Lee, I. Bello and S.T. Lee, J. Vac. Sci. Technol. B 19, 317 (2001).

10. W. Shi, H. Peng, Y. Zheng, N. Wang, N. Shang, Z. Pan, C. Lee and S. Lee, Adv. Materials 12, 1343 (2000).

11. R.S. Wagner and W.C. Ellis, Appl. Phys. Letters 4, 89 (1964).

12. N. Wang, Y.H. Tang, Y.F. Zhang, C.S. Lee, I. Bello and S. T. Lee, Chem. Phys. Letters 299, 237 (1999).

13. Y.F. Zhang, Y.H. Tang, N. Wang, C.S. Lee, I. Bello and S.T. Lee, J. Crystal Growth 197, 136 (1999).

14. Y.F. Zhang, Y.H. Tang, C. Lam, N. Wang, C.S. Lee, I. Bello and S.T. Lee, J. Crystal Growth 212, 115 (2000). 